\title{
Recurrent Headache, Coping, and Quality of Life in Children: A Review
}

\author{
Inez Bandell-Hoekstra, MSN; Huda Huijer Abu-Saad, PhD; Jan Passchier, PhD; \\ Paul Knipschild, PhD
}

Objectives.-To clarify the concepts of coping with pain and quality of life (QoL) and to present a literature review of the strategies that children with recurrent headaches use to cope with their pain, the impact of recurrent headaches on children's QoL, and the influence of personal and situational variables on headache, coping, and QoL in children.

Methods.-The literature search encompassed published articles that were found by means of a CD-ROM search of MEDLINE (1966 to December 1998) and PsycLIT (1974 to December 1998) and the snowball method.

Results.-In pediatric headache research, only three studies have been found in which children report the use of various coping strategies, and only two studies considered QoL. Demographic factors and psychological variables such as depression, anger, and anxiety influence headache prevalence. The impact of headache-related variables such as headache type, severity, perceived cause, and prior experience on QoL has only been studied in adults.

Conclusions.-More research on coping and QoL is needed in pediatric headache. The conceptual model that is presented in this article may serve as a guide.

Key words: headache, schoolchildren, coping with pain, quality of life, literature review

Abbreviations: QoL quality of life

(Headache 2000;40:357-370)

Primary headaches occur frequently in children. Without distinguishing the different headache types, recurrent headaches that occur once a week or more often are reported by more than $15 \%$ of schoolchildren. $^{1-4}$

Headache affects the individual, the family, and society. ${ }^{5}$ The impact of headache in children has been

From the Departments of Health Care Studies, Centre for Nursing Research (Mrs. Bandell-Hoekstra and Dr. Huijer Abu-Saad) and the Department of General Practice (Dr. Knipschild), Maastricht University and the Department of Medical Psychology and Psychotherapy, Erasmus University, Rotterdam (Dr. Passchier), The Netherlands.

Address all correspondence to Mrs. Inez Bandell-Hoekstra, Maastricht University, Faculty of Health Sciences, Department of Health Care Studies, Centre for Nursing Research, PO Box 616, 6200 MD Maastricht, The Netherlands.

Accepted for publication November 19, 1999. studied in terms of absenteeism from school and medical consumption..$^{6-9}$ Recently, quality of life (QoL) has been recognized as a major outcome measure of the impact of headache and its treatment. ${ }^{10,11}$ The impact of headache on a child's QoL is determined by the child's ability to cope with headache. ${ }^{12,13}$ In terms of the stress-coping paradigm, ${ }^{14}$ headache can be viewed as a stressor that requires coping. ${ }^{15}$ The underlying assumption of this approach to coping and QoL is that headache has an impact on QoL, which is influenced by coping strategies.

Another approach to coping and QoL assumes that dissatisfaction with important aspects of life becomes manifest in headaches through the influence of stress. ${ }^{16}$ The theory of stress as a headache trigger seems to be physiologically plausible for migraine and tension-type headache. ${ }^{17,18}$ Indeed, children perceive stress as an important trigger of their headaches. ${ }^{1,2,19,20}$ The underlying assumption of this ap- 


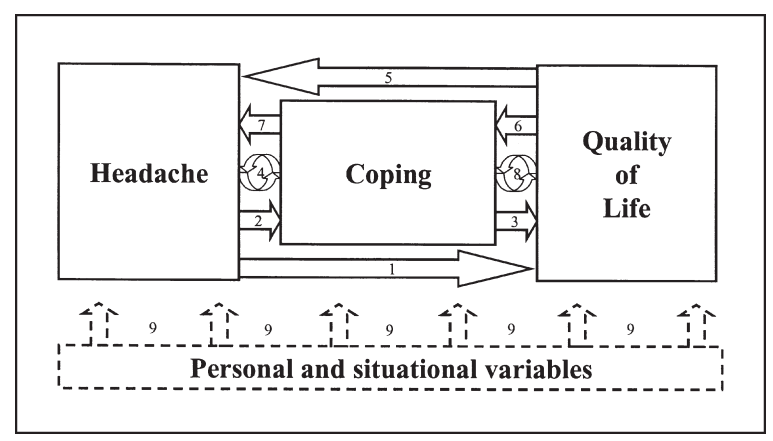

Conceptual model linking primary headache, coping, and quality of life in children.

proach to coping and QoL is that a low or diminished QoL leads to stress. Coping strategies to manage the stress may be insufficient so that the stress may trigger headache.

The two approaches to the relationship between coping and QoL in pediatric headache can be summarized in a conceptual model (Figure).

The model assumes that headache has an impact on the perceived QoL (arrow 1). Headache needs to be dealt with by using coping strategies (arrow 2). The coping strategies applied influence the QoL (arrow 3). Using strategies to cope with headache, regardless of the effect on QoL, influences the experience of headache as in a feedback loop (arrows 4). A diminished or low QoL can be perceived as a stressor, which triggers, maintains, or exacerbates headache (arrow 5). Coping strategies are required to deal with the stress (arrow 6) and influence the perceived headache (arrow 7). The strategies to cope with the stress may have an impact on the QoL as in a feedback loop (arrows 8). Headache, coping, and QoL interact in a setting of personal and situational variables (arrows 9). Demographic and personal characteristics, headache characteristics, and features of the physical and social environment ${ }^{21}$ contribute to the links between headache, coping, and QoL.

The aim of this article is to clarify the concepts of coping and QoL and to present the latest understanding of coping and QoL in pediatric headache research. Variables influencing headache, coping, and QoL in children will be reviewed here.

The literature search encompassed published articles that were found by means of a CD-ROM search of MEDLINE (1966 to December 1998) and PsycLIT
(1974 to December 1998), using the search terms headache, children, coping; headache, children, quality of life; and headache, children, psychology. In addition, the snowball method was used.

\section{COPING}

Coping can be defined as intentional cognitive and behavioral efforts to manage specific external or internal demands (and conflicts between them) that are appraised as stress because they are taxing or exceeding the resources of the person. ${ }^{22}$ Coping is a process and includes a coping goal, the coping response itself (ie, the strategy), and coping outcome. ${ }^{15,22}$ Instead of a coping strategy, the term coping skill has been suggested in order to underscore the view of coping as an ability that can be taught and used flexibly as the situation demands. ${ }^{21}$ Conversely, coping style suggests a generalized strategy or habitual preference for approaching problems, irrespective of their source or nature..$^{23}$

Classification of coping strategies into problemfocused versus emotion-focused coping distinguishes strategies directed at the distressing situation from those aimed at regulating emotions that are evoked by the event. ${ }^{14}$ Another classification distinguishes approach versus avoidance styles of coping, namely, incorporating information seeking versus information avoiding, attention versus distraction, and active versus passive strategies. ${ }^{15}$

An important theoretical component of the coping process is cognitive appraisal. Cognitive appraisal is the conscious or unconscious process of categorizing an encounter, and its various facets, with respect to its significance for well-being. ${ }^{14}$ Coping is mediated by primary and secondary cognitive appraisal. Primary appraisal concerns the question "Am I in trouble or not?" and secondary appraisal, "What, if anything, can I do and what are the consequences?"

When pain is the stressor that requires coping strategies, pain beliefs contribute to the process of appraisal and coping. They concern, for example, thoughts on the general locus of control, the controllability of pain, and the person's own ability to use specific pain responses, cognitive errors, and outcome expectations. ${ }^{24}$ 
The assessment of strategies for coping with pain in children and adolescents can be done by means of a structured interview, ${ }^{25,26}$ by showing videotaped vignettes of a child in pain to another child and asking him or her which of several proposed strategies he or she would use, ${ }^{27}$ or by using self-administered questionnaires. ${ }^{28-31}$

Structured interviews have shown that 6- to 12 year-old children with migraine use affective coping, in the form of seeking social support, to manage the emotional responses to their headaches. In addition, they use problem-focused coping and cognitive coping, in the form of thought stopping, spiritual coping, and mental distraction. ${ }^{26}$ Schoolchildren mentioned rest and relaxation as coping strategies most often, followed by cooling, analgesics, and distraction. Doing nothing to deal with their headaches was reported by $18 \%$ of schoolchildren. ${ }^{25}$ The KidCope questionnaire ${ }^{30}$ has demonstrated that the preferred strategies for coping with pain of children with recurrent headaches are as follows (in descending order): taking medicine or lying down, distraction, relaxation, seeking family support, wishful thinking, becoming helpless, problem solving, maintaining a future orientation, and remaining positive. Differences across headache types are found in that children with chronic daily headache are more likely to blame others, use problem solving, or attempt to forget the pain, when compared with children with migraine or mixed headache.

The effectiveness of coping strategies has been expressed in terms of trait-anxiety, missed days of school, the expression of more negative behavior, more pain expression, more off-task behavior, and pain-related interference with the regular activities of daily living. ${ }^{32}$ In addition, behavioral problems together with low social competency scores and absenteeism from school define "noncopers" among pediatric patients with migraine. ${ }^{26}$ Noncopers were found to have a narrower range of coping skills than copers. They depended more on social support from specific family members only, instead of from a wider, interpersonal network. They reported less use of preventive and anticipatory coping and emphasized cognitive and problem-focused coping less.

In an experimental setting, noncoping adolescents with chronic benign intractable pain showed more negative behavior (ie, verbally indicating anger, refusal, or discouragement) when they had to perform a task. They tended to complain of pain more, gave up more easily, and displayed noncompliance..$^{33}$ In general, avoidance coping appears to be associated with more positive adaptation in the short run, whereas approach coping will be associated with more positive outcomes in the long run..$^{34}$

The assessment of successful coping requires an interactional approach of person and situation. It involves at least a match between the stressor (ie, headache) and coping and, specifically in children, it needs a match between self-initiated coping and externalinitiated (eg, parent) coping. ${ }^{15}$ Assessment of this match requires the assessment of the perceived, reported, or observed influence of parents (or others) on the child's coping with pain.

In pediatric headache, the focus on coping has been primarily through cognitive-behavioral training programs. Teaching coping strategies to deal with stress and pain appears to be effective in reducing headache frequency. ${ }^{35,36}$

\section{QUALITY OF LIFE}

Quality of life is a concept that encompasses a broad range of physical and psychological characteristics and limitations that describe an individual's ability to function, and the satisfaction derived from doing so. ${ }^{37}$ Health-related QoL is an expression of individuals' perceptions of their position in life in the context of the culture and value systems in which they live and in relation to their goals, expectations, standards, and concerns. It is affected by their physical health, psychological state, level of independence, social relationships, and relationships to salient features of the environment. ${ }^{38}$ Health-related QoL is closely related to the World Health Organization (WHO) definition of health, ${ }^{39}$ which includes concepts such as disease, physical well-being and role-limitations, social well-being, general health perceptions, and satisfaction. ${ }^{40}$ Other definitions include psychological functioning as well, encompassing stress and depression among other variables. ${ }^{41}$ Thus, health-related QoL is not only a multidimensional concept, incorporating social, psychological, and physical health; it is 
also a double-sided concept because it incorporates positive as well as negative aspects of well-being and life. In addition, it is a dynamic concept that changes when health status changes. But, most importantly, it is a personal, subjective concept that should be selfassessed. ${ }^{42,43}$

In the light of this description, single indicators such as mortality and morbidity can no longer be viewed as representing health-related QoL. However, whether health-related QoL should be measured by means of profiles that produce scores on several dimensions of QoL, or by means of composite indices that aggregate several measures into one overall index, is still subject to debate. ${ }^{40,44}$

Health-related QoL can be assessed by means of disease-specific or generic measures. ${ }^{11}$ Generic questionnaires make it possible to compare QoL across diseases and clinical and research settings. The advantage of disease-specific QoL questionnaires is the emphasis on disease-specific concerns and needs, ensuring sensitivity to clinically significant changes in health status and disease severity, ${ }^{11,40,43,44}$ thereby improving reliability, validity, and acceptability. ${ }^{44} \mathrm{In}$ addition, a standardized, generic instrument to which disease-specific supplements can be added has been proposed. ${ }^{40}$

The assessment of headache-related QoL in children and adolescents has only recently started. In adolescents, an ad hoc questionnaire on $\mathrm{QoL}^{16}$ led to the development of the Quality of Life Headache in Youth (QLH-Y) questionnaire. ${ }^{41,45}$

In male adolescents, low correlations have been reported between headache frequency, intensity, and duration and dimensions of QoL. Headache frequency correlated negatively with satisfaction with health. Headache duration correlated negatively with satisfaction with autonomy, and intensity correlated negatively with satisfaction with health, satisfaction with school, satisfaction with home situation, general satisfaction, and satisfaction with autonomy. ${ }^{16}$ In adolescents with chronic headache and migraine, 4-week diary measurements of headache intensity and frequency have been compared with simultaneously recorded data on the QLH-Y questionnaire. The subscales "headache impact on daily activities," "harmony," "fatigue," "cheerful mood/good humor," "sat- isfaction with life in general," and "satisfaction with health" proved to be sensitive to changes in actual headache presence in the expected direction..$^{45}$

Health-related QoL in headache research is important for the assessment of aspects of the burden of headache on individual patients as an outcome measure in clinical trials or clinical practice, for the identification of optimal treatments and (re)allocation of resources, and for the comparison of the burdens as well as the therapeutic opportunities of various disease categories. ${ }^{10}$ No studies have been found that address these functions of QoL in children and adolescents.

Adult patients with migraine, however, reported substantially diminished functioning and well-being compared with the general population. ${ }^{46,47}$ Conversely, differences between patients with headache and the general population seem to be small. ${ }^{48}$ The largest differences have been found in measures of bodily pain, role disability due to physical health, and social functioning, ${ }^{46}$ in addition to vitality ${ }^{48}$ and role disability due to emotional problems. ${ }^{47}$ Even in between attacks, QoL seems to be impaired when compared with headache-free controls. ${ }^{49}$

Compared with patients with other chronic illnesses, adult patients with chronic headache show significantly worse physical, social, and role functioning and worse mental health. The health-related QoL of patients with chronic headache seems to be comparable to QoL after recent myocardial infarction or congestive heart failure, but lower than QoL related to arthritis, diabetes, depression, and back problems. ${ }^{50}$

The assessment of QoL has been an outcome measure of pharmacological therapeutic trials in adult patients with headache..$^{11,51-54}$ Only one recently published study using QoL as an outcome measure in a nonpharmacological trial was found. ${ }^{55}$

\section{VARIABLES INFLUENCING HEADACHE, COPING WITH PAIN, AND QUALITY OF LIFE}

Headache, coping with pain, and QoL are influenced by preexisting variables that reflect characteristics of the child and of the situation in which the 
child has to deal with the headache. Person-specific variables studied with regard to headache, coping with pain, and QoL encompass demographic variables such as age, sex, and socioeconomic status and psychological state and trait variables. Situation-specific variables include characteristics of the current headache, controllability of the headache as a consequence of perceived triggers and expectations based on prior pain experiences, and the context in which the headache starts.

Person-Specific Variables.-Demographic Variables.-Studies of the frequency of headache in children have shown an interaction between age and gender. Until the age of 10 to 12 years, the prevalence of headache is as common in boys as in girls. During and after puberty, headache is more prevalent in girls. ${ }^{2,56-60}$ Not only does the frequency of headache change during growing up, but strategies for coping with pain also develop. The number of spontaneous strategies for coping with pain increases with age, specifically with respect to cognitive strategies such as positive self-statements and attention diversion. . $^{32,61}$

Developmental stage-related changes in children's definitions and beliefs about pain, reported among both healthy ${ }^{62}$ and chronically sick ${ }^{63,64}$ children, may influence the development of the process for coping with pain, as may developmental changes in peer friendships and parental support. ${ }^{65,66}$

With regard to gender and strategies for coping with pain in general, 9- to 12-year-old girls (58\%), rather than boys (18\%), appear to be able to spontaneously present two or more strategies for coping with pain. Moreover, girls report a larger variety of strategies. ${ }^{61}$ The opposite results have been found in children and adolescents with chronic headaches in the United States. Male patients reported the use of a higher number of coping skills. Surprisingly, a threeway interaction was found between gender, race, and headache type. Irrespective of the headache type, minority males displayed the highest total number of coping strategies, while Caucasian boys reported a decrease in the number of strategies from migraine to mixed and chronic daily headache. In girls, the total number of coping strategies was equal for migraine, higher for Caucasians with mixed headaches, and higher for minorities with chronic daily headache. ${ }^{30}$
Sex differences in coping may reflect differential socialization or more inherent differences in the developmental sequence or speed of each sex. ${ }^{23}$ No studies were found in the field of pediatric headache reporting age and sex differences with regard to QoL.

Psychological Functioning.-Several studies have suggested a relationship between chronic (headache) pain and personality and the psychological characteristics of the child. Children suffering from recurrent headaches, including migraine, seem to have higher depression scores than control children, $3,67,68$ with younger children scoring twice and older children three times as high. ${ }^{69}$ Forty-one percent of 9- to 12year-old girls diagnosed with depression reported headaches compared with $9 \%$ of girls without depression, or $9 \%$ of boys in this age group..$^{70}$

In adolescents, headache is the somatic complaint that shows the highest correlation $(r=0.48)$ with depression. ${ }^{71}$ Headache is twice as common in adolescents who are depressed as in those who are not. ${ }^{72}$ Although not all pediatric studies confirm these findings, ${ }^{73,74}$ a comorbidity of migraine, as well as tension-type headache, and depression has been reported in adults..$^{75,76}$

The relationship between depression and headache may be bidirectional. ${ }^{75}$ Either way, somatic focus seems to be a mediator of the relationship. According to the neurobiological model, ${ }^{77}$ depression is accompanied by a higher degree of somatic focus, through which pain facilitation neurons will be activated, causing a stimulus to be perceived as more intense, namely, the threshold for perception of somatic pain decreases..$^{58,78}$ The psychodynamic model hypothesizes that pain may lead to higher somatic focus and, therefore, may increase depression. ${ }^{77}$ Indeed, a positive association of headache, depression, and somatic concern has been reported in children with recurrent headache. ${ }^{69,73}$ Moreover, pediatric patients with headache show more somatic symptoms and pain complaints compared with headache-free controls. ${ }^{79}$ Although the evidence remains inadequate to substantiate the view that depression precedes and generates pain in the majority of patients with chronic pain, ${ }^{80-82}$ a recent longitudinal study suggests an increased risk of early adult headache for those who suffer from depression as adolescents. ${ }^{72}$ 
Depression does not only influence the sensory aspects of pain, as can be explained by the gate control theory ${ }^{83}$ but, in addition, moderates the affective and evaluative dimensions of pain. The influence of depression on the experience of pain may be mediated by catastrophizing thoughts. In a path-analysis study of adults, catastrophizing was found to be slightly to moderately related to the sensory, evaluative, and affective dimensions of pain. ${ }^{84}$

Among adults with chronic pain, depression has been reported to be associated with higher levels of self-reported pain and pain behavior, lower levels of physical and psychosocial functioning, and poor response to treatment. ${ }^{85-88}$ Chronic pain is found to be related to more current depression and less current life satisfaction..$^{89}$ Thus, depression might be a mediator of the relationship between (migraine) headache and QoL.

Suppressed anger appears to be related to depression, ${ }^{90}$ however, the direction of the association between pain and anger remains unclear. Internalized anger may be depressed as pain, or inhibited anger may exacerbate chronic pain..$^{91}$ Anger and related concepts such as frustration, hostility, and aggression have not been studied in children with headaches. However, temperament may influence a child's responsiveness to stress and the style of coping, by tempering psychological and biological preparedness to respond to stress. ${ }^{92}$ Features of temperament, viewed as the emotional side of a child's personality, seem to be distinct in clinically referred children with migraine when compared with a control group of schoolchildren. The migrainous child shows more hyperactivity, less adaptability, less persistence, higher distractibility, and low pain threshold. ${ }^{93}$

Results of studies of the relationship between headache and anxiety are inconclusive. State-trait anxiety scores in children with migraine or recurrent headaches were found to be within the normal range and comparable to those of headache-free controls. ${ }^{67,73,74}$ However, migrainous children with higher self-rated anxiety experienced more frequent and severe headaches. ${ }^{67}$ Other studies found elevated traitanxiety scores in children with recurrent headaches when compared with controls. ${ }^{3,68,69,94}$ In children with recurrent headaches, the level of anxiety seems to in- crease from childhood through adolescence. ${ }^{95}$ The influence of anxiety on the experience of pain may be mediated by the attention that is paid to the painful situation because of anxiety. ${ }^{96}$

Fear of failure appears to be associated with headache frequency, intensity, and attributed trouble and consequences in children of 10 to 17 years of age. ${ }^{2}$ In adults, fear of failure is more often found in patients with headache than in headache-free controls. ${ }^{97}$ In the latter study, motivation to achieve was found to be more prevalent in patients with clinical headache. In addition, greater motivation to achieve has been reported in adolescents who had tensiontype headaches, with an interaction between intelligence, desire for success, and achievement. ${ }^{98}$ Adolescents with recurrent headaches seemingly spend more time on their homework than headache-free controls. ${ }^{3}$ In a nonclinical population, however, the relationship between motivation to achieve and headache measures in adolescents could not be confirmed. ${ }^{2}$

Patients with migraine might be more vulnerable to psychopathology and poor adjustment to medical conditions. In young adults, after adjustment for gender and history of major depression and anxiety disorders, migraine was found to be associated with neuroticism, but not with extroversion or psychoticism..$^{99}$ As compared with headache-free controls, more nervous problems were found in adolescents with recurrent headaches. ${ }^{3}$ With regard to QoL, neuroticism seems to be strongly correlated with negative affects, while extroversion seems related to positive affects. Self-esteem and general well-being appear to be positively associated. ${ }^{100}$

The Personality Inventory for Children (PIC) may be useful in distinguishing migrainous children from control children with regard to personality. ${ }^{68,101}$ Intellectual inhibition, inhibition of psychomotor activity and aggressiveness, inhibition of affect, ineffective use of defense against anxiety, prevalence of phobic features, and massive use of repression were found in children with migraine when compared with matched controls, using the Rorschach test of personality and temperament. ${ }^{102}$

One might conclude that a wealth of studies suggests a relationship between headache and personal- 
ity traits and psychological functioning. However, the addition of a control group with "chronic pain other than headache" to studies might show that personality and behavioral features thought to be specifically characteristic of migraine or other headache types may, rather, be the result of having a chronic pain disorder. ${ }^{73}$ In addition, a prospective, longitudinal cohort study in young adults suggests that personality features associated with migraine represent the effects of a long-lasting migraine disorder, rather than vulnerability factors for migraine. ${ }^{103}$ More research is, thus, warranted.

Situation-Specific Variables.-Headache-Related Variables.-Cross-situational variability can be related to headache or due to characteristics of the environment. Headache-related variability involves at least the type and stage of the headache and its controllability. Diagnostic criteria suggested by the International Headache Society ${ }^{104}$ distinguish headache types by means of headache cause, namely, primary versus secondary headache; headache chronicity; pain characteristics including location, intensity, and quality; and accompanying symptoms (eg, nausea, photophobia, phonophobia). The stage of the headache refers to the sequence of anticipation, encounter, and recovery. ${ }^{15}$

Adult patients with tension-type headache only vary from patients with migraine with regard to coping responses to headache by less avoidance or reduction of lights, less reduction of social contacts, less use of sleep, and more trying to go on despite pain. However, pain intensity, and not diagnostic category or headache frequency, was significantly related to coping behavior. ${ }^{105,106}$

Quality-of-life measures show, at least in adults, that tension-type headache is associated with lesser mental health and less social functioning than migraine. ${ }^{107}$ This was not confirmed in another study, however, which found the QoL of patients with tension-type headache, as well as of other patients with headache, to be comparable with or higher than that of migraineurs. ${ }^{47}$ During an attack, patients with episodic headaches are more disabled than those with chronic headache. The physical symptoms force them to lie down, thus interfering more deeply with their social life. Patients with chronic headache, however, report more emotional disturbances. In between attacks, the QoL of patients with chronic daily headache remains more compromised. Their behavior involves avoidance of social life and smoking, worrying about whether a headache will start or could worsen, fearing that others will not understand, interference with social life, and feeling fed up, not in control, frustrated, irritable, worried, and being robbed of their own time. ${ }^{108}$

When confronted with headache, secondary appraisal involves children's perception of control, which may be determined by prior experiences of headache, pain and coping strategies, perceived selfefficacy, and perceived headache triggers. Until the age of 12 years, children display a rather unidimensional definition of pain, in which they attribute their pain mainly to clearly related and immediate causes. ${ }^{109}$ However, children who have severe headaches attribute their pain mainly to tension as a result of a time-pressured daily routine, a cause that apparently has been suggested by their pediatrician. ${ }^{109}$ Indeed, parental and doctors' influences on children's perceived causes of headache must be reckoned with. ${ }^{2}$ Stress is the main headache trigger identified by children. ${ }^{2,19,20,67}$ Younger children seem less likely to acknowledge that something has triggered their headache on the day of the episode or on the day before. An especially hard day at work, school, or home, an unpleasant emotional situation, worrying a lot, unexpected excitement or pressure, tension, and happy or sad emotions were identified as stress-related headache triggers by most children, when questioned in a closed-answer format. ${ }^{20}$ In a 10 - to 17 -year-old population of schoolchildren, open-ended questions on perceived headache triggers produced the following responses, in addition to stress as the major headache trigger: lack of sleep, visual effort, heat, head injury, physical effort, suffocating atmosphere, infectious disease, noise, and intense light. ${ }^{2}$ Migrainous patients, 6 to 16 years of age, reported, again as open-ended answers, that stress, bright light, overtiredness, exercise, missing meals, and certain foods were possible headache triggers. One quarter of the children have no idea of any trigger. ${ }^{67}$ Among elementary and secondary schoolchildren, $62 \%$ and $52 \%$, respectively, do not know what causes their headache. ${ }^{2}$ Unfortunately, no 
studies have been found on the relationship between perceived trigger and subsequent coping with pain.

Prior experiences influence pain beliefs and, thus, appraisal. More experience does not necessarily imply more control or the opportunity to develop adaptive coping behaviors. ${ }^{110}$ On the contrary, negative experiences may sensitize a child to more intense feelings of pain in adolescence, compared with childhood. In a study of adolescents with juvenile rheumatoid arthritis, the pain appeared to remind the older patients of the implications of the disease, such as the possibility that the disease would affect their life and might become worse. These beliefs may have increased the severity of the pain that the patients were experiencing. ${ }^{64}$

Contributing to the development of pain beliefs is perceived self-efficacy. Efficacy expectations influence the extent to which a coping behavior will be attempted, how much persistence will be shown, and the eventual outcome. ${ }^{110}$ In addition, self-efficacy moderates the relationship between stress and headache. In adults who perceive that they have a low capacity to exercise self-control over responses to stressful events, the correlation between the frequency of stressful events and headaches is high. Increasing self-efficacy decreases the relationship between stressful events and headaches. ${ }^{111}$

Environment.-The way children experience headache is influenced by many characteristics of the environment. The role of the family, parents, or caregivers, in particular, is most prominent. Families can contribute to the pain etiology, maintain the pain problem, and deal with the impact of the pain on the family. ${ }^{112}$

A positive family history of headache has been frequently reported, specifically for migraine, $3,58,67,113,114$ but also for tension-type headache. ${ }^{115}$ Along with the inheritance of migraine, ${ }^{116}$ modeling may have an effect on the learning of cognitive processes that affect pain, as well as on the development of pain behaviors. ${ }^{117-119}$ Children of patients with chronic headache experience more headaches per month, appear to be more concerned with their body image, and report less energy than their control counterparts. ${ }^{120}$

Pain behaviors may be seen as operant behaviors that increase in frequency when the patient receives desirable consequences or is able to avoid undesir- able activities contingent upon displaying pain behaviors, namely, "secondary gain." 21 Caregivers provide discriminative cues and selective reinforcement for behavioral expressions of pain. Parental attention contingent on pain, the avoidance of nonpreferred activities, ${ }^{122}$ and parental modeling ${ }^{123}$ may affect the child's pain. Consequently, training parents to alter attending behaviors that reinforce pain behaviors into supporting their children's "healthy" behavior or active coping may be useful. ${ }^{27,124}$ Differences in motherchild interactions of adolescents who adequately or inadequately cope with chronic intractable benign pain show that mothers of noncopers more frequently discourage coping behavior. ${ }^{33}$

Family problems can also have a negative effect on headache in children. ${ }^{19}$ Adolescents with recurrent headaches are more likely to have parents who are divorced than headache-free controls. ${ }^{3}$ The relationship between culture and pain has been reported since the 1950s. ${ }^{125}$ Studies of cultural differences in the evaluative dimension of pain in pediatric patients with headache have not been found. However, prevalence figures from population-based studies of headache types in children and adolescents, mainly conducted in the Western world, appear to be internationally comparable. ${ }^{1-4,7,25,53,126-136}$

\section{CONCLUSIONS}

The associations between headache, coping with pain, and QoL are still hypothetical. Clearly, children use various coping strategies to deal with their headaches. Only two studies were found, however, that involved clinically sampled children, ${ }^{26,30}$ in addition to one population-based study using interviews..$^{25}$ The results of these studies show that almost all children with recurrent headaches report taking medication/ lying down, followed by distraction, relaxation, seeking family support, wishful thinking, becoming helpless, problem solving, maintaining a future orientation, and remaining positive..$^{30}$ In addition, forms of thought stopping, methods of mental distraction, humor, sleep, and preventive and anticipatory strategies have been mentioned, ${ }^{26}$ as well as doing nothing. ${ }^{25}$ Children seeking help for a headache problem may use coping strategies that are different from children 
who do not. In particular, population-based studies are required to gain more insight into children's strategies for coping with pain, taking into account helpseeking behavior and headache severity.

Furthermore, assessment of coping strategies in pediatric headache requires a validated questionnaire that is specifically designed for measuring coping with pain, such as the Pain Coping Questionnaire (PCQ). ${ }^{31}$ The content validity of the PCQ for headache still needs to be established.

In addition, many questions regarding coping and headache remain unanswered. Cognitive appraisal in the form of pain beliefs that influence the choice of strategies for coping with pain has not been studied in pediatric headache yet. Person-specific characteristics such as age and gender are obviously related to headache prevalence, but their relationship to coping strategies is still unclear. Certain psychological variables have been found to influence headache occurrence: depression, somatic focus, catastrophizing, anger, anxiety, fear of failure, motivation to achieve, and neuroticism. No studies have been found that focus on the impact of these variables on the use of coping strategies.

Although situation-specific characteristics such as headache intensity and chronicity have been shown to have an impact on coping with pain in adults, ${ }^{103,104}$ studies in children are lacking. Headache characteristics, accompanying symptoms, and perceived headache cause should be taken into account when studying coping strategies in children. External influences on children's strategies for coping with pain, coming from parents and peers, also present an area open for investigation.

The impact of recurrent headaches on children's QoL requires similar reflections and directions for future research. Passchier and van Knippenberg ${ }^{137}$ have reviewed several studies that focused on aspects of QoL, such as somatic complaints and general illness as part of physical well-being; anxiety, depression, emotional inhibition, and stress as part of psychological well-being; school absence, school achievement, intelligence, and social dysfunction as part of daily functioning; and satisfaction with health or happiness as a global evaluation. However, only two studies have investigated QoL as a multidimensional phenomenon in pediatric headache, both of which focus on the design of the QLH-Y questionnaire for children aged 12 years and older. ${ }^{41}$ Adaptation of the questionnaire for use in younger children needs further attention.

In particular, for the evaluation of therapeutic strategies, a larger body of studies that include QoL measures is needed. Such studies could also shed light on the direction of the relationship between headache and QoL. Studies in adults ${ }^{46-50}$ and adolescents ${ }^{45}$ have been cross-sectional until now. Although QoL in adolescents appears to be sensitive to changes in actual headache presence, ${ }^{45}$ whether headache has an impact on QoL, or poor QoL triggers the onset of headache, or whether the relationship between headache and QoL is of a reciprocal nature should be investigated. Studies in adults show a diminished QoL in patients with headache when compared with the general population. In male adolescents, headache frequency, duration, and intensity have been found to correlate negatively with satisfaction with the different aspects of QoL. ${ }^{16}$

Variables influencing headache, coping, and QoL form a complex entity, which involves person-specific and situation-specific characteristics and the relationship between both. More research is needed to unravel these relationships.

The focus in pediatric headache studies should not only be on the relationships between headache and coping with pain and headache and QoL, but it should also include the relationship between coping with pain and QoL. In addition, the nature of the interrelationship of headache, coping, and QoL needs to be addressed. The question remains whether coping is a moderator or a mediator ${ }^{138}$ of the relationship between headache and QoL. A theoretical discussion, as well as a statistical underpinning of the moderator-mediator distinction with regard to coping in pediatric headache, is needed. In this respect, the conceptual model that has been presented here may serve as a guide.

\section{REFERENCES}

1. Egermark-Eriksson I. Prevalence of headache in Swedish schoolchildren. A questionnaire survey. Acta Paediatr Scand. 1982;71:135-140. 
2. Passchier J, Orlebeke JF. Headaches and stress in schoolchildren: an epidemiological study. Cephalalgia. 1985;5:167-176.

3. Larsson B. The role of psychological, health-behaviour and medical factors in adolescent headache. Dev Med Child Neurol. 1988;30:616-625.

4. King NJ, Sharpley CF. Headache activity in children and adolescents. J Paediatr Child Health. 1990; 26:50-54.

5. Stewart WF, Lipton RB. Societal impact of headache. In: Olesen J, Tfelt-Hansen P, Welch KMA, eds. The Headaches. New York: Raven Press; 1993:29-34.

6. Collin C, Hockaday JM, Waters WE. Headache and school absence. Arch Dis Child. 1985;60:245-247.

7. Linet MS, Stewart WF, Celentano DD, Ziegler D, Sprecher M. An epidemiologic study of headache among adolescents and young adults. JAMA. 1989; 261:2211-2216.

8. Stang PE, Osterhaus JT. Impact of migraine in the United States: data from the National Health Interview Survey. Headache. 1993;33:29-35.

9. Metsähonkala L, Sillanpää M, Tuominen J. Use of health care services in childhood migraine. Headache. 1996;36:423-428.

10. Lipton RB. Health-related quality of life in headache research. Headache. 1995;35:447-448.

11. Solomon GD. Evolution of the measurement of quality of life in migraine. Neurology. 1997;48(suppl 3):S10-S15.

12. McGrath PJ, Unruh AM. Pain in Children and Adolescents. Amsterdam: Elsevier Science Publishers; 1987.

13. Bech P. Quality of life measurements in chronic disorders. Psychother Psychosom. 1993;59:1-10.

14. Lazarus RS, Folkman S. Stress, Appraisal and Coping. New York: Springer; 1984.

15. Rudolph KD, Dennig MD, Weisz JR. Determinants and consequences of children's coping in the medical setting: conceptualization, review, and critique. Psychol Bull. 1995;118:328-357.

16. van den Bree MB, Passchier J, Emmen HH. Influence of quality of life and stress coping behaviour on headaches in adolescent male students: an explorative study. Headache. 1990;30:165-168.

17. Andrasik F, Passchier J. Tension-type headache, cluster headache, and miscellaneous headaches. Psychological aspects. In: Olesen J, Tfelt-Hansen P, Welch KMA, eds. The Headaches. New York: Raven Press; 1993:489-492.

18. Passchier J, Andrasik F. Migraine. Psychological factors. In: Olesen J, Tfelt-Hansen P, Welch KMA, eds. The Headaches. New York: Raven Press; 1993: 233-240.

19. Maratos J, Wilkinson M. Migraine in children: a medical and psychiatric study. Cephalalgia. 1982;2:179-187.

20. Leviton A, Slack WV, Masek B, Bana D, Graham JR. A computerized behavioral assessment for children with headaches. Headache. 1984;24:182-185.

21. Moos RH, ed. Coping with Physical Illness. 2. New Perspectives. New York: Plenum Medical Book Co; 1984.

22. Lazarus RS. Emotion and Adaptation. New York: Oxford University Press; 1991.

23. Patterson JM, McCubbin HI. Adolescent coping style and behaviors: conceptualization and measurement. J Adolescence. 1987;10:163-186.

24. Jensen MP, Turner JA, Romano JM, Karoly P. Coping with chronic pain: a critical review of the literature. Pain. 1991;47:249-283.

25. Van Frankenberg S, Pothmann R, Müller B, Sartory G, Wolff M, Hellmeier W. Prevalence of headache in schoolchildren. In: Gallai V, Guidetti V, eds. Juvenile Headache. Etiopathogenesis, Clinical Diagnosis and Therapy. Amsterdam: Excerpta Medica; 1991:113-117.

26. Gilbert MC. Coping with pediatric migraine: differences between copers and non-copers. Child Adolesc Soc Work J. 1995;12:275-287.

27. Sanders MR, Shepherd RW, Cleghorn G, Woolford $\mathrm{H}$. The treatment of recurrent abdominal pain in children: a controlled comparison of cognitive-behavioral family intervention and standard pediatric care. J Consult Clin Psychol. 1994;62:306-314.

28. Spirito A, Stark LJ, Williams C. Development of a brief coping checklist for use with pediatric populations. J Pediatr Psychol. 1988;13:555-574.

29. Gil KM, Williams DA, Thompson RJ Jr, Kinney TR. Sickle cell disease in children and adolescents: the relation of child and parent pain coping strategies to adjustment. J Pediatr Psychol. 1991;16:643-663.

30. Holden EW, Gladstein J, Trulsen M, Wall B. Chronic daily headache in children and adolescents. Headache. 1994;34:508-514.

31. Reid GJ, Gilbert CA, McGrath PJ. The Pain Coping Questionnaire: preliminary validation. Pain. 1998;76:83-96.

32. Branson SM, Craig KD. Children's spontaneous strategies for coping with pain: a review of the literature. Can J Behav Sci. 1988;20:402-412.

33. Dunn-Geier BJ, McGrath PJ, Rourke BP, Latter J, 
D'Astous J. Adolescent chronic pain: the ability to cope. Pain. 1986;26:23-32.

34. Suls J, Fletcher B. The relative efficacy of avoidant and nonavoidant coping strategies: a meta-analysis. Health Psychol. 1985;4:249-288.

35. Richter IL, McGrath PJ, Humphreys PJ, Goodman JT, Firestone P, Keene D. Cognitive and relaxation treatment of paediatric migraine. Pain. 1986; 25:195-203.

36. Osterhaus SO, Passchier J, van der Helm-Hylkema $\mathrm{H}$, et al. Effects of behavioral psychophysiological treatment on schoolchildren with migraine in a nonclinical setting: predictors and process variables. J Pediatr Psychol. 1993;18:697-715.

37. Walker SR, Rosser RM, eds. Quality of Life: Assessment and Application. Lancaster: MTP Press; 1988.

38. WHOQOL Group. Measuring Quality of Life: The Development of the World Health Organization Quality of Life Instrument (WHOQOL). Geneva: WHO; 1993.

39. World Health Organization. International Classification of Impairments, Disabilities, and Handicaps. A Manual of Classification Relating to the Consequences of Disease. Geneva: WHO; 1980.

40. Patrick DL, Erickson P. Assessing health-related quality of life for clinical decision making. In: Walker SR, Rosser RM, eds. Quality of Life: Assessment and Application. Lancaster: MTP Press; 1988:9-49.

41. Langeveld JH, Koot HM, Loonen MC, HazebroekKampschreur AA, Passchier J. A quality of life instrument for adolescents with chronic headache. Cephalalgia. 1996;16:183-196.

42. Schipper H. Quality of life: principles of the clinical paradigm. J Psychosoc Oncol. 1990;8:171-185.

43. Bowling A. Measuring Disease. Buckingham: Open University Press; 1995.

44. McKenna SP. Quality of life assessment in the conduct of economic evaluations of medicines. $\mathrm{Br} J$ Med Econ. 1995;8:33-38.

45. Langeveld JH, Koot HM, Passchier J. Headache intensity and quality of life in adolescents. How are changes in headache intensity in adolescents related to changes in experienced quality of life? Headache. 1997;37:37-42.

46. Osterhaus JT, Townsend RJ, Gandek B, Ware JE Jr. Measuring the functional status and well-being of patients with migraine headache. Headache. 1994:34:337-343.
47. Michel P, Dartigues JF, Lindoulsi A, Henry P. Loss of productivity and quality of life in migraine sufferers among French workers: results from the GAZEL cohort. Headache. 1997;37:71-78.

48. Essink-Bot ML, van Royen L, Krabbe P, Bonsel GJ, Rutten FF. The impact of migraine on health status. Headache. 1995;35:200-206.

49. Dahlöf CG, Dimenas E. Migraine patients experience poorer subjective well-being/quality of life even between attacks. Cephalalgia. 1995;15:31-36.

50. Solomon GD, Skobieranda FG, Gragg LA. Quality of life and well-being of headache patients: measurement by the medical outcomes study instrument. Headache. 1993;33:351-358.

51. Miller DW, Osterhaus JT, Hirsch JD, Gutterman DL. Quality of life assessment among migraineurs treated with sumatriptan: preliminary findings [abstract]. Headache. 1993;33:278.

52. Kirchberger I, Bullinger M, Bruggenjurgen B. Quality of life in migraine treatment. Results of a longitudinal study using the SF-36 survey. Qual Life Res. 1994;3:83.

53. Boureau F, Chazot G, Emile J, Bertin L, d'Allens $\mathrm{H}$. Comparison of subcutaneous sumatriptan with usual acute treatments for migraine. Eur Neurol. 1995;35:264-269.

54. Solomon GD, Skobieranda FG, Genzen JR. Quality of life assessment among migraine patients treated with sumatriptan. Headache. 1995;35:449-454.

55. Mannix LK, Chandurkar RS, Rybicki LA, Tusek DL, Solomon GD. Effect of guided imagery on quality of life for patients with chronic tension-type headache. Headache. 1999;39:326-334.

56. Bille B. Migraine in childhood and its prognosis. Cephalalgia. 1981;1:71-75.

57. Stewart WF, Lipton RB, Celentano DD, Reed ML. Prevalence of migraine headache in the United States. Relation to age, income, race, and other sociodemographic factors. JAMA. 1992;267:64-69.

58. Mortimer MJ, Kay J, Jaron A. Epidemiology of headache and childhood migraine in an urban general practice using Ad Hoc, Vahlquist and IHS criteria. Dev Med Child Neurol. 1992;34:1095-1101.

59. Kristjánsdóttir G, Wahlberg V. Sociodemographic differences in the prevalence of self-reported headache in Icelandic school-children. Headache. 1993; 33:376-380.

60. Sillanpää M, Anttila P. Increasing prevalence of headache in 7-year-old schoolchildren. Headache. 1996;36:466-470. 
61. Tesler MD, Wegner C, Savedra M, Gibbons PT, Ward JA. Coping strategies of children in pain. Issues Compr Pediatr Nurs. 1981;5:351-359.

62. Steward MS, Steward DS. Children's conceptions of medical procedure. In: Bibace R, Walsh ME, eds. Children's Conceptions of Health, Illness and Bodily Functions. San Francisco, Calif: Jossey-Bay; 1981:67-84.

63. Brewster AB. Chronically ill hospitalized children's concepts of their illness. Pediatrics. 1982;69:355-362.

64. Beales JG, Holt PJ, Keen JH, Mellor VP. Children with juvenile chronic arthritis: their beliefs about their illness and therapy. Ann Rheum Dis. 1983;42: 481-486.

65. Leiderman PH. Social ecology and childbirth: the newborn nursery as environmental stressor. In: Garmezy N, Rutter M, eds. Stress, Coping \& Development in Children. New York, NY: McGrawHill Book Co; 1983:133-159.

66. Eiser C. Coping with chronic childhood diseases: implications for counseling children and adolescents. Couns Psychol Q. 1989;2:323-336.

67. Cooper PJ, Bawden HN, Camfield PR, Camfield CS. Anxiety and life events in childhood migraine. Pediatrics. 1987;79:999-1004.

68. Guidetti V, Fornara K, Ottaviano S, Petrilli A, Seri $S$, Cortesi F. Personality inventory for children and childhood migraine. A case-controlled study. Cephalalgia. 1987;7:225-230.

69. Andrasik F, Kabela E, Quinn S, Attanasio V, Blanchard EB, Rosenblum EL. Psychological functioning of children who have recurrent migraine. Pain. 1988;34:43-52.

70. Egger HL, Angold A, Costello EJ. Headaches and psychopathology in children and adolescents. $J$ Am Acad Child Adolesc Psychiatry. 1998;37:951-958.

71. Larsson BS. Somatic complaints and their relationship to depressive symptoms in Swedish adolescents. J Child Psychol Psychiatry. 1991;32:821-832.

72. Pine DS, Cohen P, Brook J. The association between major depression and headache: results of a longitudinal epidemiologic study in youth. $J$ Child Adolesc Psychopharmacol. 1996;6:153-164.

73. Cunningham SJ, McGrath PJ, Ferguson HB, et al. Personality and behavioural characteristics in pediatric migraine. Headache. 1987;27:16-20.

74. Kowal A, Pritchard D. Psychological characteristics of children who suffer from headache: a research note. J Child Psychol Psychiatry. 1990;31:637-649.
75. Breslau N, Davis GC, Schultz LR, Peterson EL. Migraine and major depression: a longitudinal study. Headache. 1994;34:387-393.

76. Ho KH, Ong BK, Lee SC. Headache and selfassessed depression scores in Singapore University undergraduates. Headache. 1997;37:26-30.

77. Fields H. Depression and pain. A neurobiological model. Neuropsychiatry Neuropsychol Behav Neurol. 1991;4:83-92.

78. Geisser ME, Gaskin ME, Robinson ME, Greene AF. The relationship of depression and somatic focus to experimental and clinical pain in chronic pain patients. Psychol Health. 1993;8:405-415.

79. Carlsson J, Larsson B, Mark A. Psychosocial functioning in schoolchildren with recurrent headaches. Headache. 1996;36:77-82.

80. Romano JA, Turner JA. Chronic pain and depression: does the evidence support a relationship? Psychol Bull. 1985;97:18-34.

81. Roy R. Engel's pain-prone disorder patient: 25 years after. Psychother Psychosom. 1985;43:126-135.

82. Gupta M. Is chronic pain a variant of depressive illness? Can J Psychiatry. 1986;31:241-248.

83. Melzack R, Wall PD. The Challenge of Pain. Hamondsworth: Penguin Books; 1982.

84. Geisser ME, Robinson ME, Keefe FJ, Weiner ML. Catastrophizing, depression and the sensory, affective and evaluative aspects of chronic pain. Pain. 1994;59:79-83.

85. Blanchard EB, Andrasik F, Neff DF, et al. Biofeedback and relaxation training with three kinds of headache: treatment effects and their prediction. J Consult Clin Psychol. 1982;50:562-575.

86. Keefe FJ, Wilkins RH, Cook WA Jr, Crisson JE, Muhlbaier LH. Depression, pain, and pain behavior. J Consult Clin Psychol. 1986;54:665-669.

87. Kerns RD, Haythornthwaite JA. Depression among chronic pain patients: cognitive-behavioral analysis and effect on rehabilitation outcome. J Consult Clin Psychol. 1988;56:870-876.

88. Haythornthwaite JA, Sieber WJ, Kerns RD. Depression and the chronic pain experience. Pain. 1991;46:177-184.

89. Gamsa A. Is emotional disturbance a precipitator or a consequence of chronic pain? Pain. 1990;42: 183-195.

90. Fernandez E, Turk DC. The scope and significance of anger in the experience of chronic pain. Pain. 1995;61:165-175. 
91. Tschannen TA, Duckro PN, Margolis RB, Tomazic TJ. The relationship of anger, depression, and perceived disability among headache patients. Headache. 1992;32:501-503.

92. Kagan J. Stress and coping in early development. In: Garmezy N, Rutter M, eds. Stress, Coping and Development in Children. New York: McGrawHill; 1983:191-216.

93. Ottaviano S, Guidetti V, Innocenzi M, Baldini L, Ottaviano P, Ottaviano C. Temperament and migraine. In: Gallai V, Guidetti V, eds. Juvenile Headache. Etiopathogenesis, Clinical Diagnosis and Therapy. Amsterdam: Excerpta Medica; 1991:125-128.

94. Bille B. Migraine in school children. Acta Paediatr Scand. 1962;5(suppl):136.

95. Martin SE, Smith MS. Psychosocial factors in recurrent pediatric headache. Pediatr Ann. 1995;24: 464-474.

96. Arntz A, Dreessen L, Merckelbach H. Attention, not anxiety, influences pain. Behav Res Ther. 1991; 29:41-50.

97. Passchier J, van der Helm-Hylkema H, Orlebeke JF. Personality and headache type: a controlled study. Headache. 1984;24:140-146.

98. Rangaswamy K. Tension headaches in adolescents. J Psychol Res. 1982;26:70-72.

99. Breslau N, Andreski P. Migraine, personality, and psychiatric comorbidity. Headache. 1995;35:382-386.

100. Watten RG, Vassend O, Syversen JL, Myhrer T. Personality and quality of life. Soc Ind Res. 1995;35: 289-302.

101. Romoli M, Ardovini C, Bruni O, Diamanti R, Fornara R, Guidetti V. Childhood and adolescence headache and migraine: analysis of personality through Personality Inventory for Children. In: Gallai V, Guidetti V, eds. Juvenile Headache. Etiopathogenesis, Clinical Diagnosis and Therapy. Amsterdam: Excerpta Medica; 1991:507-509.

102. Guidetti V, Mazzei G, Ottaviano S, Pagliarini M, Paolella A, Seri S. The utilization of the Rorschach test in a case-controlled study. Cephalalgia. 1986;6: 87-93.

103. Merikangas KR, Stevens DE, Angst J. Headache and personality: results of a community sample of young adults. J Psychiatr Res. 1993;27:187-196.

104. Headache Classification Committee of the International Headache Society. Classification and diagnostic criteria for headache disorders, cranial neuralgias and facial pain. Cephalalgia. 1988;8(suppl 7):10-73.
105. Appelbaum KA, Radnitz CL, Blanchard EB, Prins A. The Pain Behavior Questionnaire (PBQ): a global report of pain behavior in chronic headache. Headache. 1988;28:53-58.

106. Scharff L, Turk DC, Marcus DA. Triggers of headache episodes and coping responses of headache diagnostic groups. Headache. 1995;35:397-403.

107. Solomon GD, Skobieranda FG, Gragg LA. Does quality of life differ among headache diagnoses? Analysis using the medical outcomes study instrument. Headache. 1994;34:143-147.

108. Cavallini A, Micieli G, Bussone G, Rossi F, Nappi G. Headache and quality of life [published correction appears in Headache. 1995;35:314]. Headache. 1995;35:29-35.

109. Ross DM, Ross SA. Assessment of pediatric pain: an overview. Issues Compr Pediatr Nurs. 1988;11: 73-91.

110. Siegel LJ, Smith KE. Children's strategies for coping with pain. Pediatrician. 1989;16:110-118.

111. Marlowe N. Self-efficacy moderates the impact of stressful events on headache. Headache. 1998;38: 662-667.

112. Turk DC, Flor H, Rudy TE. Pain and families. I. Etiology, maintenance, and psychosocial impact. Pain. 1987;30:3-27.

113. Messinger HB, Spierings EL, Vincent AJ, Lebbink J. Headache and family history. Cephalalgia. 1991; 11:13-18.

114. Russell MB, Hilden J, Sørensen SA, Olesen J. Familial occurrence of migraine without aura and migraine with aura. Neurology. 1993;43:1369-1373.

115. Turkat ID, Kuczmierczyk AR, Adams HE. An investigation of the aetiology of chronic headache. The role of headache models. Br J Psychiatry. 1984; 145:665-666.

116. Sørensen SA, Araki S. Background to the headaches. Genetics. In: Olesen J, Tfelt-Hansen P, Welch KMA, eds. The Headaches. New York: Raven Press; 1993:21-27.

117. Edwards PW, Zeichner A, Kuczmierczyk A, Boczkowski J. Familial pain models: the relationship between family history of pain and current pain experience. Pain. 1985;21:379-384.

118. Lavigne JV, Schulein MJ, Hahn YS. Psychological aspects of painful medical conditions in children. II. Personality factors, family characteristics and treatment. Pain. 1986;27:147-169.

119. Ehde DM, Holm JE, Metzger DL. The role of fam- 
ily structure, functioning, and pain modeling in headache. Headache. 1991;31:35-40.

120. Mikail SF, von Baeyer CL. Pain, somatic focus, and emotional adjustment in children of chronic headache sufferers and controls. Soc Sci Med. 1990;31:51-59.

121. Fordyce WE. Behavioral Methods for Chronic Pain and Illness. St. Louis, Mo: Mosby; 1976.

122. Philips HC. Avoidance behaviour and its role in sustaining chronic pain. Behav Res Ther. 1987;25: 273-279.

123. Whitehead WE, Busch CM, Heller BR, Costa PT Jr. Social learning influences on menstrual symptoms and illness behavior. Health Psychol. 1986;5: 13-23.

124. Beames L, Sanders MR, Bor W. The role of parent training in the cognitive behavioral treatment of children's headaches. Behav Psychother. 1992;20: 167-180.

125. Zborowski M. People in pain. San Francisco, Calif: Jossey-Bass; 1969.

126. Dalsgaard-Nielsen T, Engberg-Pedersen H, Holm HE. Clinical and statistical investigations of the epidemiology of migraine. Dan Med Bull. 1970;17:138-148.

127. Øster J. Recurrent abdominal pain, headache and limb pains in children and adolescents. Pediatrics. 1972;50:429-436.

128. Sillanpää M. Prevalence of migraine and other headache in Finnish children starting school. Headache. 1976;15:288-290.

129. Deubner DC. An epidemiologic study of migraine and headache in 10-20 year olds. Headache. 1977; 17:173-180.

130. Sillanpää M. Prevalence of headache in prepuberty. Headache. 1983;23:10-14.
131. Sillanpää M. Changes in the prevalence of migraine and other headaches during the first seven school years. Headache. 1983;23:15-19.

132. Camarda RM, Cammalleri R, Cuccia F, et al. Epidemiological and clinical study of migraine headaches in a juvenile population. In: Gallai V, Guidetti V, eds. Juvenile Headache. Etiopathogenesis, Clinical Diagnosis and Therapy. Amsterdam: Excerpta Medica; 1991:107-108.

133. Alfvén G. The covariation of common psychosomatic symptoms among children from socio-economically differing residential areas. An epidemiological study. Acta Paediatr. 1993;82:484-487.

134. Abu-Arefeh I, Russell G. Prevalence of headache and migraine in schoolchildren. BMJ. 1994;309:765-769.

135. Borge AI, Nordhagen R, Moe B, Botten G, Bakketeig LS. Prevalence and persistence of stomach ache and headache among children. Follow-up of a cohort of Norwegian children from 4 to 10 years of age. Acta Paediatr. 1994;83:433-437.

136. Barea LM, Tannhauser M, Rotta NT. An epidemiologic study of headache among children and adolescents of southern Brazil. Cephalalgia. 1996;16: 545-549.

137. Passchier J, van Knippenberg FC. Relevance and limitations of quality of life measurements in juvenile patients with chronic headaches. In: Gallai V, Guidetti V, eds. Juvenile Headache. Etiopathogenesis, Clinical Diagnosis and Therapy. Amsterdam: Excerpta Medica; 1991:449-455.

138. Baron RM, Kenny DA. The moderator-mediator variable distinction in social psychological research: conceptual, strategic, and statistical considerations. J Pers Soc Psychol. 1986;51:1173-1182. 